\title{
DONATION/PRESERVATION
}

\section{Risk Factors for Delayed Renal Graft Function and Their Impact on Renal Transplantation Outcome}

\author{
A. Figueiredo, P. Moreira, B. Parada, P. Nunes, F. Macário, C. Bastos, and A. Mota
}

\begin{abstract}
Objective. The objective of this study was to evaluate the risk factors for delayed graft function (DGF) and their influence on renal graft outcome.

Patients and Methods. We reviewed 1462 consecutive renal transplantation and identified 245 patients $(17.1 \%)$ with delayed graft function and 1120 patients with immediate graft function. Forty-one cases were excluded because of a nonfunctioning graft as well as 26 other cases because of insufficient data. We compared the incidence, donor and recipient risk factors, and impact on graft outcomes, as well as patient and graft survival of delayed graft function.
\end{abstract}

Results. Donor weight and age, recipient weight, age, length of dialysis, and cold ischemia time were significantly higher in the delayed graft function group. Higher rates of acute rejection and chronic graft dysfunction were observed in this group of patients; we also observed worse graft function and survival.

Conclusions. Multiple risk factors are associated with delayed graft function, which contribute decisively to a worse outcome.

$\mathrm{D}$ ELAYED renal graft function is defined as the need for dialysis within the first week posttransplantation, acute tubular necrosis is its most common cause. However, the consequences far exceed the transient need for dialysis because it may interfere with long-term graft survival. Our purpose was to evaluate the risk factors for delayed renal graft function and to measure their influence on renal graft outcomes.

\section{PATIENTS AND METHODS}

We retrospectively studied 1462 consecutive renal transplantations performed between 1980 and 2005. All relevant data concerning the donor, the recipient, and the transplantation were inserted into a database. The percentages of patients with immediate diuresis versus delayed graft function (DGF) were calculated. We evaluated risk factors for the occurrence of DGF, either donor-related or recipient-related. Also, the patient and graft survival rates, as well as long-term renal function, were evaluated.

Of the 1462 procedures, we excluded 41 cases (2.8\%) of never-

From the Department of Urology and Renal Transplantation, Hospitais da Universidade de Coimbra, Portugal.

Address reprint requests to A. Figueiredo, Department of Urology and Renal Transplantation, Hospitals da Universidade de Coimbra, 3049 Coïmbra Codex, Portugal. E-mail: ajcfigueiredo@gmail.com

0041-1345/07/\$-see front matter doi:10.1016/j.transproceed.2007.07.032 
functioning renal grafts, as well as 26 because of insufficient data. Of the remaining 1395 procedures, $1120(82.9 \%)$ had immediate graft function (IGF), and $245(17.1 \%)$ had DGF.

Immunosupression protocols were similar between the 2 groups: in the IGF group, induction with either antithymocyte globulin, OKT3, or anti-CD25 (basiliximab) was given to $22.2 \%$ of cases, whereas in the DGF group, it was given to $21.2 \%$.

For maintenance therapy, the IGF group received the following: azathioprine + prednisone, $2.1 \%$; CyA + azathioprine + prednisone, $50.0 \%$; CyA + mycophenolate + prednisone, $26.2 \%$; tacrolimus + mycophenolate + prednisone, $7.3 \%$; CyA + sirolimus + prednisone, $1.6 \%$; Mycophenolate + sirolimus + prednisone, $6.6 \%$; Tacrolimus + sirolimus + prednisone, $1.8 \%$; Sirolimus + mycophenolate + prednisone, $2.1 \%$; CyA + everolimus + prednisone, $0.8 \%$; or for azathioprine + tacrolimus, $0.5 \%$.

The DGF group received the following: azathioprine + prednisone, 3.7\%; CyA + azathioprine + prednisone, $41.6 \%$; CyA + mycophenolate + prednisone, $29.0 \%$; tacrolimus + mycophenolate + prednisone, $10.6 \%$; CyA + sirolimus + prednisone, $2.4 \%$; mycophenolate + sirolimus + prednisone, $6.1 \%$; tacrolimus + sirolimus + prednisone, $2.4 \%$; sirolimus + mycophenolate + prednisone, $2.0 \%$; mycophenolate + prednisone, $0.4 \%$; CyA + everolimus + prednisone, $1.2 \%$; or azathioprine + tacrolimus, $0.4 \%$.

The differences were not significant.

The demographic characteristics of each of the groups were compared for donor and recipient factors as well as patient and graft survivals, acute rejection rates, and renal function.

The statistical analysis was performed using SPSS 11.5 (SPSS Inc., Chicago, Ill, USA) with Chi-square tests for quantitative variables, Students $t$ test for continuous variables, and KaplanMeier survival curves. Statistical significance was considered when $P \leq .05$.

\section{RESULTS}

Mean donor weight was $66.9 \pm 18.8 \mathrm{~kg}$ in the IGF group, whereas in the DGF group it was $72.8 \pm 17.8$, a significant difference $(P=.005)$. Donor age was significantly lower in the IGF than the DGF group $(32.2 \pm 14.4$ vs $36.3 \pm 17.29$, respectively; $P=.000)$. Donor urinary output was significantly higher in the IGF $(347.5 \pm 369.1 \mathrm{~mL} / \mathrm{h})$ than the DGF group $(287.4 \pm 298.5 \mathrm{~mL} / \mathrm{h} ; P=.009)$. Also, in the IGF group, cranial trauma was responsible for donor death in $87.4 \%$ of the cases, whereas in the DGF group it was responsible for $70.4 \%$ of the cases, a significant difference $(P=.000)$.

Mean recipient weight was significantly lower in the IGF $(62.0 \pm 13.2 \mathrm{~kg})$ than the DGF group $(64.0 \pm 15.7 \mathrm{~kg} ; P=$ $.043)$. Recipient age was also significantly lower in the IGF $(40.6 \pm 13.8)$ than the DGF group $(43.4 \pm 13.3 ; P=.005)$. Previous dialysis time was $35.1 \pm 33.2$ months for the IGF and for the DGF group it was $48.3 \pm 40.8$ months, a significant difference $(P=.000)$. Cold ischemia time was significantly shorter in the IGF $(19.7 \pm 6.5$ hours $)$ than the group (22.1 \pm 6.6 hours; $P=.000)$. Acute rejection episodes occurred in $33.2 \%$ of patients within the IGF group versus $47.7 \%$ in the DGF group, a significant difference $(P=.000)$.

Chronic graft dysfunction was lower in the IGF $(23.4 \%)$ than the DGF group (35.6\%), also significant $(P=.001)$.
Table 1. Risk Factors and Transplant Evolution: Comparison of Immediate Diuresis and DGF Groups

\begin{tabular}{lccc}
\hline & $\begin{array}{c}\text { Immediate } \\
\text { Diuresis }\end{array}$ & DGF & $P$ \\
\hline Donor weight $(\mathrm{kg})$ & $66.9 \pm 18.8$ & $72.8 \pm 17.8$ & .005 \\
Donor age & $32.2 \pm 14.4$ & $36.3 \pm 17.29$ & .000 \\
Donor urinary output $(\mathrm{mL} / \mathrm{h})$ & $347.5 \pm 369.1$ & $287.4 \pm 298.5$ & .009 \\
Recipient age & $40.6 \pm 13.8$ & $43.4 \pm 13.3$ & .005 \\
Recipient weight $(\mathrm{kg})$ & $62.0 \pm 13.2$ & $64.0 \pm 15.7$ & .043 \\
Previous dialysis $(\mathrm{mo})$ & $35.1 \pm 33.2$ & $48.3 \pm 40.8$ & .000 \\
Cold ischemia time $(\mathrm{h})$ & $19.7 \pm 6.5$ & $22.1 \pm 6.6$ & .000 \\
Creatinine $(\mathrm{mg} / \mathrm{dL})$ & & & \\
$\quad 1 \mathrm{~m}$ & $1.4 \pm 0.6$ & $2.8 \pm 2.1$ & .000 \\
$1 \mathrm{y}$ & $1.3 \pm 0.4$ & $1.6 \pm 0.8$ & .000 \\
$10 \mathrm{y}$ & $1.4 \pm 0.8$ & $1.7 \pm 1.3$ & $\mathrm{NS}$ \\
Acute rejection & $33.2 \%$ & $47.7 \%$ & .000 \\
Chronic graft disfunction & $23.4 \%$ & $35.6 \%$ & .001 \\
Graft survival & & & \\
$1 \mathrm{y}$ & $94.9 \%$ & $84.4 \%$ & .000 \\
$5 \mathrm{y}$ & $82.6 \%$ & $68.4 \%$ & \\
$10 \mathrm{y}$ & $65.0 \%$ & $52.9 \%$ & \\
\hline
\end{tabular}

Mean plasma creatinine level as 1 month was $1.4 \pm 0.6$ $\mathrm{mg} / \mathrm{dL}$ in the IGF group versus a significantly higher value $(2.8 \pm 2.1 \mathrm{mg} / \mathrm{dL} ; P=.000)$. In the DGF group. At 1 year posttransplantation this value was $1.3 \pm 0.4 \mathrm{mg} / \mathrm{dL}$ in the IGF group and $1.6 \pm 0.8 \mathrm{mg} / \mathrm{dL}$ in the DGF group $(P=$ $.000)$, whereas at 10 years, it was $1.4 \pm 0.8 \mathrm{mg} / \mathrm{dL}$ vs $1.7 \pm$ 0.7 , respectively $(P=$ not significant $[\mathrm{NS}])$.

Graft survival at 1 year was $94.9 \%$ in the IGF group, and $91.3 \%$ in the DGF group. At 5 years it was $91.1 \%$ in the IGF and $81.1 \%$ in the DGF group, whereas at 10 years it was $65.0 \%$ and $52.9 \%$, respectively. Survival was significantly better in the IGF group $(P=.000)$.

Patient survival rate at 1 year was $97.4 \%$ in the IGF group, and $84.4 \%$ in the DGF group. At 5 years it was $82.6 \%$ in the IGF group and $68.4 \%$ in the DGF group, whereas at 10 years it was $81.1 \%$ and $71.4 \%$, respectively. These differences were not significant (Table 1).

Also, no significant differences were observed between the 2 groups regarding the number of HLA-compatible antigens. IGF group had $49.4 \% 3$ or more compatible antigens, whereas the DGF group had $52.3 \%$.

\section{DISCUSSION}

Our study disclosed more risk factors for DGF than other studies, ${ }^{1,2}$ which may be due to the larger number of transplantations. Cold ischemia time appears as an important risk factor, consistent with other studies. ${ }^{2,3}$ It is a potential target to reduce the risk of DGF. However, most of the other risk factors are predetermined and not amenable to correction. We observed significantly better graft survival among grafts with immediate function, but not all studies have demonstrated this fimeley. ${ }^{4}$

In conclusion, DGF is associated with multiple risk factors: donor weight, age, cause of death, and urinary output; recipient weight, age, and time on dialysis; as well as 
cold ischemia time. It contributes decisively to worse graft outcomes, higher rates of acute rejection and chronic graft dysfunction, as well as worse graft function and survival.

\section{REFERENCES}

1. Parzanese I, Maccarone D, Caniglia L, et al: Risk factors that can influence kidney transplant outcome. Transplant Proc 38:1022, 2006
2. Quiroga I, McShane P, Koo DD, et al: Major effects of delayed graft function and cold ischaemia time on renal allograft survival. Nephrol Dial Transplant 21:1689, 2006

3. Lebranchu Y, Halimi JM, Bock A, et al: Delayed graft function: risk factors, consequences and parameters affecting outcome-results from MOST, A Multinational Observational Study. Transplant Proc 37:345, 2005

4. Pieringer $\mathrm{H}$, Biesenbach $\mathrm{G}$ : Risk factors for delayed kidney function and impact of delayed function on patient and graft survival in adult graft recipients. Clin Transplant 19:391, 2005 